\title{
Tendências das mudanças da proteção social no Brasil e no Uruguai: a centralidade das redes mínimas na América Latina
}

\author{
Alejandra Pastorini \\ Universidade Federal do Rio de Janeiro (UFRJ)
}

\author{
Inés Martínez \\ Universidad de la República (Udelar)
}

Tendências das mudanças da proteção social no Brasil e no Uruguai: a centralidade das redes mínimas na América Latina

Resumo: O objetivo deste trabalho é compreender as alterações na lógica que orienta o trato das manifestações da questão social na atualidade, tomando como referência a realidade do Brasil e do Uruguai. Inicia-se pela análise das mudanças contemporâneas nas sociedades capitalistas, prestando especial atenção nas alterações dos princípios que estruturam a proteção social. Dessa forma, identifica-se algumas tendências das reformas nas políticas sociais nos governos progressistas que se consolidam na virada do século. Palavras-chave: Capitalismo contemporâneo. Questão social. Proteção social.

Trends of Changes in Social Protection in Brazil and Uruguay: the centrality of the minimal networks in Latin America

Abstract: The purpose of this study is to understand the changes in the logic that guides handling of the social question today, using as a reference realities found in Brazil and Uruguay. It begins with an analysis of contemporary changes in capitalist societies, giving special attention to the changes in the principles that structure social protection. In this way, it identifies some trends in the reforms in social policies in the progressive governments that took office at the turn of the century.

Keywords: Contemporary capitalism. Social question. Social protection. 


\section{Introdução}

Nas últimas décadas, as políticas sociais, nos diferentes países capitalistas, sofrem mudanças importantes tanto nos seus princípios e lógicas quanto nos seus desenhos e objetivos. Essas alterações vinculam-se intimamente com as novas requisições do Estado burguês no estágio atual do capitalismo, na busca para assegurar e conservar a dominação e exploração de classe. Por conseguinte, identificar o contexto em que essas mudanças se produzem torna-se central para decifrar as principais tendências das reformas da proteção social. Nossas reflexões se concentrarão em pensar as mudanças nos mecanismos de proteção tendo como marco a crise do capital que emergiu em meados dos anos 1970 indicando a saturação do padrão de acumulação até então vigente.

Aqui destacamos o papel central que o Banco Mundial vem tendo no processo de transformação da proteção social na América Latina, tomando como referência o caso de Uruguai e do Brasil, países onde podem ser identificadas mudanças importantes nas expressões da questão social, assim como nas formas que o Estado (e/ou o sociedade civil) utiliza para amenizá-las. Dentre essas alterações se destacam a presença e a importância que as redes mínimas de assistência vêm assumindo nas últimas décadas.

Neste trabalho nos guiaremos pela ideia que a partir de início do século 21, no contexto de avanço dos "governos progressistas" da região, a lógica que orienta as ações sociais direcionadas para aliviar as manifestações imediatas da questão social distanciam-se da noção de proteção social (baseada numa lógica redistributiva e democrática) e se aproximam de uma lógica controladora e repressiva, reforçando o caráter punitivo e coercitivo do Estado.

\section{0 capitalismo contemporâneo e as ondas de reformas nas políticas sociais}

A partir dos anos 1970, o processo de acumulação comandado pelo capital financeiro articulado aos grandes grupos industriais transnacionalizados (IAMAMOTO, 2007) requer uma reorganização da produção e dos processos de gestão e controle da força de trabalho nela inseridos juntamente com mecanismos diferentes para administrar a superpopulação relativa. Neste contexto hegemonizado pelo capital financeiro, o Estado, atingido pelas reformas de orientação neoliberal ${ }^{1}$, desenvolve suas funções econômicas diretas e indiretas de forma distinta na busca por criar condições de valorização e acumulação do grande capital especulativo.

A partir da segunda metade dos anos 1980 esses processos de reformas (dentre as quais se destacam a do Estado e da proteção social) começam a expandir-se pelo mundo capitalista graças à participação dos organismos financeiros multilaterais (Banco Mundial, Fundo Monetário Internacional e o Banco Interamericano de Desenvolvimento) que buscam criar as condições para atender às necessidades do grande capital. Como indicam Pastorini e Galizia (2006), os empréstimos destes organismos encontravam-se condicionados à implementação das reformas, que foram um dos mecanismos utilizados para fazer avançar esses processos de mudanças. As reformas têm como ponto de arranque o Consenso de Washington e o "pacote de ajuste estrutural" que inclui o combate da inflação através de estabilidade monetária, disciplina orçamentária, reforma fiscal etc. Esse conjunto de reformas foi posteriormente adjetivado como de "primeira geração". Tais reformas incluíram programas combate da inflação, reforma da previdência social, privatizações das empresas públicas, reformas da educação etc.

Mesmo sendo possível identificar elementos comuns e até um caráter mundializado dessas reformas nas sociedades capitalistas, elas objetivaram-se com particularidades regionais, nacionais, políticas, culturais etc. Portanto, faz-se necessário considerar as determinações concretas das diferentes formações sociais, levando em conta o desenvolvimento das forças produtivas, as relações entre classes e setores de classes, o legado histórico, a organização dos sujeitos políticos, dentre outras determinações.

As investigações mais recentes de Boschetti (2012) trazem importantes elementos para sumariar as tendências das reformas da proteção social acontecidas na Europa, a partir da década de 1990 até a entrada do século 21. Se, por um lado, é possível identificar que essas reformas tomaram rumos diferenciados até meados dos anos 1990, por outro, a autora nos alerta para o fato de que as posteriores mudanças na proteção social europeia, sob o comando da União Europeia e dos organismos de financiamento multilateral, concentram-se na busca por consolidar as políticas de ativação do emprego (sem proteção, mal remunerado e sujeito a condicionalidades), no estímulo das redes mínimas de proteção para os trabalhadores pobres e na redução dos sistemas universais públicos como forma de incentivar a autoproteção.

A realidade dos países do Cone Sul da América Latina, inseridos de forma dependente na periferia do capitalismo, apresenta importantes diferenças com as sociedades acima mencionadas, em especial quando se busca analisar as mudanças acontecidas na proteção social, embora seja possível identificar elementos comuns. 
Pensando no caso do Uruguai, foi a partir da segunda metade dos anos 1980 (com o fim dos governos ditatoriais) que começam a serem executadas as reformas com claras tendências liberalizadoras em âmbito econômico, que serão aprofundadas ao longo dos anos $1990^{2}$. Elas vieram acompanhadas de importantes transformações da proteção social, caracterizada até então pelo universalismo estratificado, a elevada cobertura, a lógica redistributiva e a solidariedade entre os trabalhadores protegidos. Segundo Midaglia et al. (2007) dentre as principais reformas sociais implementadas no período dos governos dos partidos tradicionais estão: a suspensão dos mecanismos de negociação salarial ${ }^{3}$, a criação de um segundo pilar do sistema de aposentadoria baseado no regime de capitalização individual e administrado pelo setor privado, a reformulação e criação de um conjunto de programas e projetos focalizados nos setores mais pobres e em grupos etários considerados mais vulneráveis (crianças e adolescentes). No Uruguai foi registrada uma versão neoliberal menos avassaladora se comparada com as experiências argentina, chilena e brasileira, devido ao fato de que a reforma do Estado uruguaio, impulsionada pelos partidos tradicionais, no início dos anos 1990 (sob o governo de Luis Alberto Lacalle, Partido Nacional), conseguiu ser parcialmente detida pelo Plebiscito de 1992, contra a chamada Lei de Empresas Públicas (que buscava impor o processo de privatização). Os mecanismos de democracia direta - plebiscitos e referendum ${ }^{4}$ impulsionados como resposta a este processo neoliberalizador, transformaram-se em uma ferramenta essencial para os setores de esquerda (organizações dos trabalhadores como os sindicatos, movimentos sociais e partidos políticos) em suas lutas contra as imposições regressivas na restauração democrática. Foram quatro os momentos em que essa estratégia foi utilizada com êxito para deter as propostas apresentadas pelos setores conservadores: a reforma das aposentadorias (em 1989 e 1994) ${ }^{5}$, a revogação parcial da Lei de Empresas Públicas (em 1992) ${ }^{6}$ e a revogação da Lei da Desmonopolização da empresa estatal de petróleo (em 2003). Houve outro conjunto de consultas populares cujos assuntos centrais foram: os programas de reforma do Estado (que concentrou sete consultas), a Lei de Inversões ${ }^{7}$, a Lei de Seguridade Social ${ }^{8}$ e a Lei de Urgência ${ }^{9}$. Também aconteceram duas outras iniciativas relativas à reforma política e quatro reivindicações por parte de grupos específicos (aposentados, sindicatos da educação e Poder Judiciário) (MOREIRA, 2004, p. 32).

$\mathrm{O}$ avanço do projeto reformador teve no Brasil uma cronologia diferenciada da sociedade uruguaia, uma vez que a implementação do ideário neoliberal, e o conjunto de reformas a ele articulado, acontece de forma tardia se comparado com a experiência mencionada anteriormente e a de outros países da região, que aderiram às políticas econômicas e sociais neoliberais na segunda metade da década de 1980 e reformaram os Estados nos anos 1990. Foi a partir do primeiro governo Fernando Henrique Cardoso que o Brasil começa a implementar as reformas neoliberais, dentre elas a denominada contrarreforma ${ }^{10}$ do Estado, programas de privatização das empresas públicas, processo de reestruturação produtiva etc.

Preocupados aqui em pensar as políticas sociais na

... expande-se pelo mundo capitalista, e em especial nos

países latino-americanos, 0 denominado paradigma da pobreza como diretriz central do novo desenho das políticas e programas sociais. atualidade, concentraremos nossa atenção em alguns elementos comuns que guiaram essas reformas, tanto no Brasil quanto no Uruguai, para além das particularidades de cada formação social. Primeiro, cabe citar que o alvo das críticas dos defensores das reformas era os sistemas tradicionais de proteção social estruturados nas primeiras décadas do século 20 - principalmente nos governos de Vargas e Batlle orientados pelos princípios da solidariedade entre contribuinte, atendimento a riscos coletivos, participação do Estado na sua administração e co-financiamento dos sistemas. Em segundo lugar, essas reformas partem da premissa que $o$ Estado moderno e competitivo não pode mais continuar a ser o protagonista no atendimento das manifestações da questão social. Dessa forma, a provisão dos serviços e benefícios sociais será mais eficiente e eficaz quanto maior for a parceria com as entidades e organizações preocupadas com a proteção dos direitos sociais (ONGs, organizações sociais, fundações etc.). O terceiro elemento diz respeito às políticas e programas sociais de caráter emergencial que passam a estar orientados pela ideia da focalização nas populações mais pobres e na necessidade de definir critérios de elegibilidade e de estruturar testes de meios para corrigir desvios da seletividade. Entretanto, essas novas intervenções sociais, implementadas pelas entidades e organizações sem fins lucrativos, não foram capazes de constituir uma rede sólida de assistência articulada com as demais ações e políticas sociais, contribuindo, nesse sentido, para reforçar o caráter dual da proteção social em ambos os países ${ }^{11}$.

Nesse contexto de avanço das reformas neoliberais, as ações na área de assistência social direcionadas para os setores mais pauperizados passam por mudanças importantes. No Brasil, a assistência social, após a 
aprovação da Constituição Federal de 1988, é reconhecida, pela primeira vez, como uma política pública integrante do tripé da Seguridade Social. Essa transformação constitui um importante avanço para se incorporar, no âmbito do Estado, extensos setores da população historicamente excluídos da proteção social e que ficavam a mercê da caridade e da filantropia ${ }^{12}$.

Entretanto, no Uruguai, é nesse contexto de avanço das reformas neoliberais que a assistência social, direcionada para setores mais pauperizados, começa a ter uma maior visibilidade como estratégia setorial de atendimento. A assistência nesse país, desde inícios do século 20, caracteriza-se por uma trajetória intersetorial, implicando num conjunto de ações que perpassavam várias políticas setoriais, em especial a saúde e previdência, ao mesmo tempo em que complementavam outras políticas públicas. Em diferentes momentos da história uruguaia existiram ações e programas assistenciais tanto para trabalhadores inseridos no mercado de trabalho ${ }^{13}$ quanto para aqueles não inseridos, ou sem vínculos formais de emprego ${ }^{14}$. Entretanto, fazendo uma comparação com o desenvolvimento institucional das outras políticas sociais, percebe-se que a assistência uruguaia teve uma função subsidiária e complementar das políticas sociais estruturantes da proteção social (previdência, saúde, educação e emprego). O certo é que o caráter e importância da assistência social têm mudado essencialmente nos últimos anos. Embora tenha adquirido uma centralidade que não tinha antes, continua a manter seu caráter intersetorial, fato que a obriga a fazer referência constante às demais políticas sociais.

\section{A redução da questão social à questão da pobreza}

Tal como afirmamos acima, a nova dinâmica mundial sob hegemonia do capital financeiro e especulativo requisita uma nova organização e intervenção do Estado para criar as condições para o processo de valorização e acumulação. Essas mudanças foram impostas mundialmente, contando mais uma vez com a participação dos organismos multilaterais que redefinem algumas das diretrizes que guiaram as reformas neoliberais (dominadas pela ortodoxia monetarista), dando lugar às conhecidas reformas de segunda geração.

As políticas do Consenso de Washington começam a ser questionadas, por um lado, perante as sucessivas e explosivas expressões localizadas e generalizadas da crise estrutural. Por outro lado, o panorama político em vários países da América do Sul estava sendo redefinido, seja pela ascensão de governos identificados com a esquerda e/ou centro-esquerda, seja pelo aumento das mobilizações e lutas que expressavam o desacordo ou descontentamento com as políticas de ajuste neoliberal e/ou seus custos sociais ${ }^{15}$.

As críticas dos opositores da política macroeconômica e da estratégia de desenvolvimento de orientação neoliberal e as autocríticas realizadas pelo Banco Mundial e seus colaboradore ${ }^{16}$ coincidiram num ponto: nos últimos anos presenciou-se um aumento nos índices da pobreza, da concentração de renda e das desigualdades sociais. A constatação do agravamento da questão social, nesse contexto político-econômico mundial, contribuiu para reconhecer a necessidade de se adotar posições menos ortodoxas, dando lugar à segunda geração das reformas.

Essas reformas, tomando-se como pressuposto que políticas eficazes têm que se assentar em instituições sólidas, colocam a ênfase nas reformas institucionais, mostrando-se ao mesmo tempo favoráveis a estilos distantes da "ortodoxia monetarista" e "abertos à inovação" (GONÇALVES, 2012).

Existe um afastamento da postura anterior daquelas propostas de Bretton Woods que buscaram implementar um único e idêntico pacote de ajuste estrutural nos diferentes países da região latino-americana e que não considerava as particularidades de cada formação social. Destaca-se agora a necessidade de se levar em conta as diferenças econômicas, políticas e culturais entre os países e de se colocar no centro das preocupações a busca pela criação de formas e estratégias de "coesão" e legitimação social (PASTORINI, 2012).

Esses estilos menos ortodoxos e abertos à inovação propostos pelos defensores da segunda geração das reformas requerem um distanciamento tanto da proposta neoliberal do Estado mínimo quanto das experiências dos Estados sociais. É nesse contexto de reformas, e pensando especificamente nas estruturas e mecanismos de proteção social, que os organismos de financiamento multilateral como Banco Mundial (BIRD) e Banco Interamericano de Desenvolvimento (BID) passam a basear seus programas e políticas em quatro grandes diretrizes, a saber: a definição das metas de redução da pobreza, a consolidação de redes de seguridade social, o estímulo às reformas que regulem e incentivem a participação do setor privado em áreas concebidas como não exclusivas do Estado (como, por exemplo, os setores que atendem os direitos sociais) e busca da governabilidade.

Neste processo de reformulação das estratégias de intervenção das organizações multilaterais, o Banco Mundial assume um lugar de destaque, tanto em termos políticos quanto teóricos. As produções e ações do Banco, além de contribuírem com a redução da questão social a uma questão de pobreza absoluta, reforçam o processo de enquadramento das políticas sociais no conjunto de programas e ações direcionadas ao alívio da pobreza. 
Por conseguinte, expande-se pelo mundo capitalista, e em especial nos países latino-americanos, o denominado paradigma da pobreza como diretriz central do novo desenho das políticas e programas sociais. Este paradigma pode ser entendido como um conjunto de elaborações técnico-teóricas desenvolvidas de forma especial pelos organismos multilaterais - mas adotadas pelos governantes e defendidas pela academia - que, na busca por atender as manifestações imediatas da questão social (identificadas com o desemprego estrutural, pobreza absoluta e violência), perdem o vínculo com a riqueza (ou seja, com o processo de sua produção, reprodução e apropriação) e com o emprego como referências para estruturar as intervenções públicas, reforçando assim as ações e programas setoriais, focalizados na pobreza e individualizados.

Essas elaborações concebem a superpopulação relativa como um problema dado e natural, que teria que ser enfrentado através de mecanismos compensatórios (como os programas de transferência de renda, inclusão produtiva, fomento do empreendedorismo etc.). Na medida em que essas manifestações da questão social são consideradas insolúveis, as intervenções no social tornam-se mecanismos de controle e/ou de reintegração. Nesta interpretação, onde é identificado um deslocamento do mecanismo integrador na sociedade contemporânea (que desliza do trabalho para a pobreza absoluta), as principais causas dos problemas que atingem a maioria dos trabalhadores são individualizadas e os riscos sociais interpretados como decorrências da precária ou inexistente inserção no mercado de trabalho, associado com a localização territorial dessas populações empobrecidas e com as características singulares (idade, sexo, religião, cultura, constituição familiar, laços sociais etc.) predominantes nesses grupos. Reduzindo a questão social à pobreza absoluta e perdendo os vínculos com a totalidade social a questão social é transformada num problema técnico passível de solução através de ações eficazes e eficientes.

Essa busca por atingir metas de pobreza (metas de redução e/ou eliminação da pobreza que poderiam ser alcançadas sem a alteração dos fundamentos da sociedade burguesa) articula-se, de forma íntima, com uma segunda diretriz que diz respeito à consolidação de redes mínimas de atendimento. A incidência e/ou exposição aos riscos sociais contribui, segundo as elaborações do Banco Mundial, para transformar as classes subalternas em grupos vulneráveis e, portanto, destinatários principais das ações focalizadas, ou seja, os programas assistenciais, o atendimento básico em saúde e ensino fundamental. Essas redes mínimas de atendimento social, focalizadas nos setores mais empobrecidos, são concebidas como mecanismos mais eficazes e eficientes que as políticas sociais universalistas.

A ampliação dessas redes conta com a participação direta das entidades e organizações da sociedade civil, dentre elas as ONGs, organizações sociais, fundações e associações sociais. Entretanto, o Estado continuará a cumprir um papel central, já não mais como provedor direto dos bens e serviços, mas regulando juridicamente (ou seja, criando as condições legais para aumentar a participação e protagonismo do setor privado) e financiando (direta ou indiretamente a implementação das intervenções desse setor), fomentando-se assim uma importante mudança na relação público/privado. Também é necessário mencionar que a ampliação das redes mínimas de seguridade social focalizadas nos setores mais pauperizados é acompanhada do processo de redução e/ou deterioração das políticas públicas que sustentam a proteção social - previdência, educação e saúde.

Junto com esta estratégia de aumento e participação do setor privado há um quarto elemento constitutivo das diretrizes do Banco Mundial que merece ser mencionado: a consolidação de estratégias político-ideológicas para a redução das tensões e lutas sociais. Estamos fazendo referência, por um lado, ao processo indicado por Zibechi (2011, p. 18), que concentra os esforços "na contenção do comunismo, e na derrota e disciplinamento no campo popular", e, por outro lado, ao desenvolvimento de práticas de controle e ocupação dos territórios considerados de risco. Essa estratégia de controle e repressão tem como peça central o "processo de criminalização das expressões da questão social e dos grupos, organizações, sujeitos e movimentos sociais que resistem ou contra-atacam essa estratégia" (PASTORINI, 2012, p. 9). A combinação dessas duas táticas será importante para a manutenção da ordem e da governabilidade (permitindo aos governantes de plantão o exercício do poder político para poder administrar política e economicamente a nação).

Esse último elemento contribui com a redução do caráter protetivo do Estado e o aumento da dimensão repressiva e coercitiva, cedendo cada vez mais espaços para a consolidação do Estado punitivo, nas palavras de Wacquant (2007). Essas mudanças no caráter da intervenção do Estado passam a obter cada vez maior apoio político-econômico de diferentes setores da sociedade perante a "extensão das novas narrativas, atores e situações que promovem a insegurança e elaboram uma cultura do medo como figura onipresente (...). [Dessa forma] o medo, a insegurança e a violência passaram a ser importantes fatores de coesão social" (MORÁS, 2010, p. 16).

Nesse sentido afirmamos que, nos últimos anos, tanto as produções dos técnicos em políticas públicas como dos teóricos vinculados à academia e dos governantes à esquerda no espectro político, na América Latina, vêm aderindo às diretrizes propostas pelo Banco Mundial e/ou contribuindo com a construção dos caminhos que conduzam à sua consolidação nos países da região. 


\section{Tendências das reformas sociais dos governos progressistas no Brasil e no Uruguai}

As chamadas reformas de segunda geração e a redefinição das intervenções no social, baseadas nas diretrizes propostas pelos organismos multilaterais, inserem-se em uma mudança estratégica necessária de acordo com discurso da classe dominante, a partir da virada do século, devido às mudanças no panorama político dos países localizados na periferia do capitalismo e perante o agravamento das crises econômicas e políticas que afetaram duramente a região.

Um dado importante para pensar a realidade desses países do Cone Sul da América Latina é a chegada ao governo nacional de setores que representavam os anseios da maioria dos trabalhadores identificados de forma geral com os princípios e valores defendidos historicamente pela esquerda. A partir dos primeiros anos do século 21 expandem-se pela região os denominados governos progressistas ${ }^{17}$.

Entretanto, importa mencionar que esses governos "não optaram pelo abandono das diretrizes impostas pelos organismos de financiamento internacional e nem anularam a dívida externa, não implementaram uma reforma agrária e, tampouco colocaram limites ao grande capital" (PASTORINI, 2012, p.7). Especificamente pensando no social, poderíamos afirmar que esses governos tampouco conseguiram fugir das orientações e diretrizes propostas pelo Banco Mundial e reforçadas pelo BID: esta instituição passa a ter um papel decisivo na redefinição das políticas sociais, do ponto de vista teórico, ideopolítico e financeiro.

Quando o Frente Amplio (FA) assume o governo nacional do Uruguai em 2005, depara-se com a difícil tarefa de enfrentar as consequências das reformas estruturais implementadas no país a partir da segunda metade de 1980 e, em particular, ao longo dos anos 90. Amarante et al. (2005) indicam que a partir de 1999, a economia uruguaia começou uma etapa de recessão, que se traduziu numa crise econômica e social sem precedentes, provocando queda nas reservas do Banco Central, redução do PIB, aumento da inflação. Ademais, os indicadores sociais acompanharam esse movimento mostrando o aumento dos índices de pobreza absoluta (atingindo 33\%, em 2002) e indigência, redução de $20 \%$ da renda familiar e a explosão do desemprego, que chegou a $19 \%$ da população economicamente ativa.

Perante essa realidade de crise e com o intuito de honrar as promessas de campanha que teve como bandeira a luta "contra a fome", cria-se no primeiro ano de governo de Vázquez (FA) o Programa de Atención Nacional para la Emergencia Social (PANES), a pedra fundamental da estratégia de emergência social (nutricional e sanitária). Esse programa guarda-chuva vinculou-se institucionalmente ao MIDES (Ministério de Desenvolvimento Social, criado também em 2005) tendo como componente fundamental o programa de transferência de renda, condicionado e focalizado na extrema pobreza, denominado Ingreso Ciudadano.

Em 2007, entrou em vigor a reforma tributária ${ }^{18}$ e em 2008 inicia-se a reforma do Sistema de Saúde (com a implementação do Sistema Nacional Integrado de Saúde - SNIS). Cada uma dessas reformas explicitava um conjunto de objetivos que poderiam ser resumidos em: incluir os setores excluídos da proteção social e equilibrar os custos do atendimento dos diversos setores (aproximando os recursos destinados aos trabalhadores inseridos no mercado formal de trabalho e aos mais pauperizados). Essas duas reformas foram os pilares que sustentaram o Plan de Equidad, criado em 2007, em substituição ao PANES.

Este novo Plano é apresentado como um mecanismo estratégico para reorganizar a proteção social no Uruguai, promovendo um conjunto de transformações, tanto na previdência social quanto nas ações assistenciais. Pretende criar uma nova matriz de proteção integrada por componentes estruturais (reforma tributária, da saúde, políticas de emprego, política de habitação, reforma educativa etc.) e por componentes específicos que consistiriam em uma moderna rede de assistência e integração social (transferência de renda, segurança alimentar, educação para infância e adolescentes, empreendimentos produtivos, inclusão social, dentre outros) (URUGUAI, 2008). Dentre os componentes estruturais, a reforma tributária e a da saúde começaram a ser implementadas; no entanto, as principais mudanças aconteceram nos chamados componentes específicos, e, de forma mais significativa, os esforços se concentraram na consolidação da rede de assistência com destaque nos programas de transferência de renda condicionados, assistência à velhice, auxílio moradia etc. ${ }^{19}$

Entretanto, a implementação desses programas e as ações focalizadas na pobreza (pilar do PANES e do Plan de Equidad) se constituíram em elementos centrais nesse período. Como consequência, a criação do MIDES vai se consolidando como uma lógica de atendimento às necessidades sociais das populações mais pauperizadas, distinta da que predominara anteriormente no país, distanciando-se do modelo de proteção que começou a ser implantado nas primeiras décadas do século 20. É interessante mencionar que o Uruguai tinha, até os anos 1970, taxas elevadas de formalização do emprego (que permitiu garantir uma cobertura social de $95 \%$ da população economicamente ativa), o que tornou possível a universalização da proteção pela via da inserção laboral. Dentro dessa dinâmica, as ações conhecidas como de assistência eram concebidas como complementares (e necessariamente articuladas) com as diferentes políticas sociais permanentes de corte mais universalista. 
Por outro lado, nos últimos anos percebe-se uma expansão do paradigma da pobreza como orientador da gestão dos programas sociais, incorporado pelos diferentes governos ao longo nos anos 1990. Faz parte desse paradigma, para além da preocupação em reduzir os índices de pobreza absoluta, a preocupação em criar uma estrutura e uma logística que permita, aos técnicos e profissionais envolvidos implementar as ações sociais, definir o universo de beneficiários (através da identificação e comprovação da vulnerabilidade e/ou risco) e controlar o andamento dos atendimentos de forma eficaz e eficiente. Importa mencionar que, se no caso das transferências de renda, o Estado continua a ser o responsável pela sua gestão, a realidade muda quando analisamos o conjunto de programas e ações sociais vinculadas a essas transferências (programas sócio-educativos, de geração de emprego e renda, de inclusão social etc.) onde as organizações e entidades privadas assumem destaque.

Vários analistas da experiência desenvolvida no Uruguai insistem em afirmar que parte das mudanças na matriz de proteção foi espelhada no processo desenvolvido no Brasil, a partir do primeiro governo de Luiz Inácio Lula da Silva. A experiência brasileira apresenta várias semelhanças com o caso anteriormente mencionado: um primeiro elemento diz respeito à centralidade que vêm assumindo as ações assistenciais dentro do conjunto das intervenções para atender às manifestações da questão social (como pobreza, violência, desemprego etc.), insinuando que essas expressões das desigualdades próprias da sociedade capitalista poderiam ser resolvidas através de políticas sociais mais eficazes e eficientes. Também é a partir da década de 1990, e, de forma mais organizada, no início do século 21, que os programas de transferência de renda assumem centralidade e vinculam-se estreitamente com os programas de reforma (sejam eles concebidos como de primeira ou de segunda geração). Esses programas, concebidos como inovações em termos de planejamento público, são considerados como instrumentos indispensáveis para se atingir as metas de redução da pobreza.

Os programas de transferência de renda focalizados na pobreza (a exemplo do Bolsa Família, do Brasil sem Miséria etc.) são uma das peças fundamentais das redes mínimas de atendimento no social direcionadas para as populações vulneráveis e em situação de risco que decorre, como define a Lei $12.435^{20}$, da fragilização dos vínculos familiares e sociais, da violação dos direitos, dentre outras situações que requerem a intervenção do Estado e das entidades e organizações da assistência social sem fins lucrativos. Entretanto, perante o agravamento da questão social, esses programas e ações assistenciais vão modificando seu caráter emergencial e temporário, transformando-se em permanentes e principais vias de acesso ao atendimento social dos setores pauperizados.

\section{Considerações finais}

Queremos fechar estas reflexões reafirmando nossa convicção de que para analisar as mudanças na proteção social e, dentro desta, as particularidades da assistência social, não se deve desconsiderar a importância que estas intervenções do Estado burguês possuem para os processos de produção e reprodução social. Tampouco poderemos relegar a um segundo plano tanto as transformações acontecidas na organização do processo de acumulação quanto as novas requisições postas para o Estado na contemporaneidade.

Essas relações nos permitirão refletir o sentido das mudanças das políticas econômicas imbricadas de forma íntima com um formato particular de políticas sociais. Portanto, entendemos que a forma peculiar que assumem as estratégias de intervenção do Estado - direcionadas para atender as manifestações da questão social - mais do que uma consequência das mudanças societárias contemporâneas, constituem-se em uma peça central dessas transformações que expressam, ao mesmo tempo, a correlação de forças presentes nessa sociedade.

Importa destacar mais um elemento que indica uma inflexão nas estratégias de atendimento das manifestações da questão social na atualidade, componente que pode ser identificado tanto no Uruguai quanto no Brasil e que se refere à ampliação da presença das ações de controle, punitivas e repressivas por parte do poder público para com as classes subalternas. Autores como Morás (2010) indicam que, a partir de 2010, pode ser percebida, no Uruguai, uma mudança no desenho das políticas de seguridade, que indicaria o abandono do horizonte da emergência social colocando no seu lugar a emergência carcerária. Segundo o autor, esse processo estaria sendo alavancado pelo aumento do sentimento de insegurança da população (alimentado pela mídia) e pelo discurso do agravamento da violência (mesmo que o número de cidadãos presos aumente mais que os delitos cometidos), sugerindo o abandono de uma visão otimista baseada principalmente no tratamento das causas da violência e reforçando o controle e a repressão sobre as consequências.

Concordamos com o autor que esse elemento pode indicar uma tendência na transformação dos princípios que fundamentam as intervenções do poder público na contemporaneidade: o encarceramento massivo de populações de baixa renda, os grupos de extermínio, o controle e repressão policial, os programas de "pacificação" e outros poderiam ser indícios dessa mudança. Concomitantemente, constata-se que as ações e progra- 
mas assistenciais tendem cada vez mais a se articularem com variadas práticas de controle e de ocupação de espaços considerados de risco, com diferentes estratégias que buscam a integração à ordem vigente dos indivíduos, grupos e movimentos sociais.

\section{Referências}

AMARANTE, V. et al. El mercado laboral: cambios estructurales y el impacto de la crisis, 1986-2002. In: AMARANTE, V. et al. Uruguay: empleo y protección social, de la crisis al crecimiento. Santiago de Chile: Oficina Internacional del Trabajo (OIT), 2005, p. 39-138.

BEHRING, E. R. Brasil em contra-reforma: desestruturação do Estado e perda de direitos. São Paulo: Cortez, 2008.

BOSCHETTI, I. A insidiosa corrosão dos sistemas de proteção social europeus. Serviço Social \& Sociedade. São Paulo: Cortez, n. 112, p.754-803, out./dez. 2012.

GONÇALVES, R. Novo desenvolvimentismo e liberalismo enraizado. Serviço Social \& Sociedade. São Paulo: Cortez, n. 112, p. 637671, out./dez. 2012.

IAMAMOTO, M. V. Serviço Social em tempo de capital fetiche. Capital financeiro, trabalho e questão social. São Paulo: Cortez, 2007. NETTO, J. P. Crise do socialismo e ofensiva neoliberal. São Paulo: Cortez, 1995.

MIDAGLIA, C. et al. La izquierda en el gobierno: ¿cambio o continuidad en las políticas de bienestar social? Revista Uruguaya de Ciencia Política. Montevideo: IPC/Udelar, v. 1, n. 16, p. 131-157, dez. 2007.

MORÁS, L. E. Los dilemas y desafíos de las políticas progresistas de seguridad. Revista Encuentros Uruguayos. Montevideo, n. 3, p. 6-21, set. 2010.

MOREIRA, C. Resistencia política y ciudadanía: plebiscitos y referéndums en el Uruguay de los '90. Revista América Latina Hoy. Salamanca: Ediciones Universidad de Salamanca, n. 36, p.17-45, abr. 2004.

PASTORINI, A. Transformações societárias e questão social: as políticas sociais no capitalismo contemporâneo. In: ENCONTRO NACIONAL DE PESQUISADORES EM SERVIÇO SOCIAL, 2012. Juiz de Fora: Anais... Juiz de Fora: UFJF, 2012.

PASTORINI, A.; GALIZIA, S. A Redefinição do Padrão de Proteção Social Brasileiro. Revista Praia Vermelha. Rio de Janeiro: PPGSS/ UFRJ, v. 1, n. 14-15, p. 72-103, set. 2006.

SOARES, L. T. Os custos sociais do ajuste neoliberal na América Latina. São Paulo: Cortez, 2000.

URUGUAI, Ministério de Desenvolvimento Social. Plan de Equidad. Montevidéu, 2008. Disponível em: <http://www.mides.gub.uy/ equidad/documentos/plan_equidad_def.pdf $>$. Acesso em: 10 jan. 2013.

WACQUANT, L. Punir os pobres. A nova gestão da miséria nos Estados Unidos. Rio de Janeiro: Revan, 2007.

ZIBECHI, R. Política e miseria: la relación entre el modelo extractivo, los planes sociales y los gobiernos progresistas. Buenos Aires: Lavaca, 2011.

\section{Notas}

1 Como indica Netto (1995, p.76), as reformas apoiam-se nas elaborações de Hayek e Friedman que restauram "o mercado como instância mediadora societal elementare insuperável e uma posição política que repõe o Estado mínimo como única alternativa e forma para a democracia".

2 Oregime ditatorial (1973-1985) que operou em sintonia com as correntes restauradoras, impulsionou uma maior abertura econômica, liberalização e desregulação que significaram o começo da fase "pós-batllista" do Estado uruguaio. Assim, os governos conservadores da restauração democrática (Sanguinetti 1985-1990e 1995-2000, Lacalle 1990-1995 e Batlle 2000-2005) continuaram com a política da abertura econômica, acompanhada pelo estrito controle do gasto público. Este panorama de reformas e políticas de ajuste se encontrava em clara harmonia com as propostas e diretrizes definidas pelos organismos multilaterais como FMI e Banco Mundial.

3 Os Conselhos de Salários (CS) são uma importante instância de negociação entre os trabalhadores, empregadores e o Estado que, organizados por ramos de atividade, têm como objetivo fixar o valor dos salários mínimos (chamados "laudos"), por setor. Os CS foram criados em 1943, pela Lei n. 10.449, e passaram por diferentes etapas. Durante o período da ditadura (1968-1985) e ao longo da década de 1990, os CS não foram convocados pelos governos; somente vão ser retomados, em 2005, no governo de Tabaré Vázquez.

4 Segundo a legislação uruguaia, o plebiscito tem caráter constitucional e deliberativo com a finalidade de aprovar as alterações do texto constitucionais, enquanto o referendum é utilizado para revogar leis já aprovadas. O primeiro plebiscito no Uruguai data de 1917 e o primeiro referendum nacional realizou-se em 1987, com o intuito de revogar a Ley de Caducidad (ou Lei de Anistia, como foi chamada). Para convocar um plebiscito se requer à adesão de 10\% dos cidadãos uruguaios, e a convocação de um referendum necessita do apoio de pelo menos 25\% (MOREIRA, 2004, p. 28).

5 Esta resposta impediu que o Poder Executivo pudesse modificar as aposentadorias nas leis de prestação de contas anuais. Esse recurso obteve $72 \%$ de adesão (MOREIRA, 2004, p. 36).

6 O objetivo central da Lei era facilitar o processo de privatização de grandes empresas públicas, como o Banco de Seguros e a refinaria de petróleo, assim como permitir a participação de empresas privadas em outras empresas estatais (na área de telecomunicações, energia etc.).

7 Esta lei alegava a necessidade da flexibilização das leis trabalhistas como imperativo para aumentar os investimentos privados estrangeiros.

8 Esta lei promoveu a criação das administradoras de fundos de previdência e pensão individual, administrados por empresas privadas. 
9 Trata-se de uma modalidade específica, que possui menos requisitos para sua aprovação, neste caso, proposto no final da década de 1990: buscava-se novamente a liberalização e desregulamentação de alguns setores produtivos.

10 Behring (2008, p. 24) argumenta que na década de 1990 aconteceu a contrarreforma do Estado brasileiro, entendendo-a como um processo diferente da modernização conservadora. As reformas dos anos 1990 consolidam-se como mudanças estruturais que têm como traços fundamentais o caráter fortemente destrutivo e regressivo, "bastante diferente das 'fugas para a frente' do desenvolvimentismo". Assim, a autora aponta que usar o termo "reforma" nas mudanças impulsionadas no neoliberalismoé cometer uma injustiça com a tradição dessa noção, mais fortemente atrelada às transformações progressistas do que aos retrocessos no acesso aos direitos e ao aumento da pauperização.

11 Para aprofundar a discussão acerca do processo de dualização da proteção social no Brasil, consultar Soares (2000) e, no Uruguai, consultar Midaglia et al. (2007).

12 É importante esclarecer que, após a aprovação da LOAS, foi necessário um longo processo de luta política para conseguir sua implementação.

13 Neste caso, os benefícios assistenciais outorgados eram entendidos como uma decorrência e alargamento dos direitos já conquistados pela inserção no mercado de trabalho (exemplo da AFAM que consista na transferência de uma renda por fillho para todos os contribuintes da previdência).

14 Quase sempre vinculados a serviços de pouca qualidade, viabilizados de forma estigmatizante, como exemplo: a exigência de comprovação, por parte do usuário, da sua impossibilidade de acessar o sistema privado de saúde, como critério para ser atendido no sistema público.

15 Podemos mencionar como exemplo: o caracazo de 1989, o movimento dos desempregados e piqueteros na Argentina, os Zapatistas no México, o Movimento dos Trabalhadores Rurais Sem Terra (MST) no Brasil, dentre outros.

16 Como indica Gonçalves (2012,p. 656), as críticas concentraram-se no fato de que o Consenso de Washington guiou-se por "diretrizes equivocadas e, principalmente, incompletas, e havia necessidade de reformas de segunda geração. Surgiu, então, o chamado Pós-Consenso de Washington (também conhecido como Consenso de Washington Ampliado), que coloca ênfase nas reformas institucionais".

17 Trata-se de governos que, apesar das diferenças e particularidades que assumem as suas trajetórias, possuem elementos comuns. Por exemplo: orientam-se por um discurso anti-imperialista, promovem a liberdade e igualdade social, defendem a possibilidade de uma estratégia de desenvolvimento nacional como caminho para obter crescimento econômico, equidade e justiça social. Exemplos são Vázquez e Mujica (no Uruguai), Nestor Kirchner e Cristina Kirchner (na Argentina), Lula da Silva e Rousseff (no Brasil), Lagos e Bachelet (no Chile).

18 Traz como transformação fundamental a mudança da tributação sobre o salário - Imposto sobre as retribuições (IRP) - para a tributação sobre a renda-Imposto sobre as Rendas Pessoais (IRPF). Diversos pesquisadores demonstram que o IRPF comparado com o IRP seria um mecanismo de tributação mais progressivo.

19 No caso da experiência uruguaia, a organização de uma parte importante dos programas de transferência de renda utilizou a estrutura criada na década de 1940, por as Asignaciones Familiares - AFAM, beneficio proporcional à quantidade de filhos, recebido por todo trabalhador contribuinte com a previdência. A partir de 2008, instaura-se um novo regime deAFAM, nos marcos do Plan de Equidad, que estende o benefício a todos os lares em situação de vulnerabilidade socioeconômica, independentemente do vínculo com o mercado de trabalho, aumenta os valores das transferências, define a mulher como responsável etc.

20 Lei aprovada em julho de 2011 que altera a LOAS e normatiza a criação do Sistema Único de Assistência Social (SUAS) no território brasileiro.

\section{Alejandra Pastorini}

alejandrapastorini@gmail.com

Doutora em Serviço Social pela Universidade Federal do Rio de Janeiro (UFRJ)

Professora do Departamento de Política Social e Serviço Social Aplicado da Escola de Serviço Social da UFRJ

\section{UFRJ - Departamento de Política Social e Serviço Social Aplicado}

Av. Pasteur, 250 - Fundos, Praia Vermelha.

Rio de Janeiro - Rio de Janeiro - Brasil

CEP: $22290-240$

\section{Inés Martínez}

ines.martinez@cienciassociales.edu.uy

Mestre em Serviço Social pela Universidade Federal do Rio de Janeiro (UFRJ)

Professora do Departamento de Trabajo Social da Universidad de la República (Udelar)

\section{Udelar - Facultad de Ciencias Sociales}

Rua Constituyente 1502

Montevideo - Uruguai

CEP: 11200 